\title{
'Connected ka pa ba?': A study on how social media usage affects face-to-face interactions within the home.
}

\author{
Marie Grace A. dela Vega ${ }^{a}$, Rodelyn B. Flores ${ }^{\mathrm{b}}$, Avon Joyce M. Magusib ${ }^{\mathrm{c}}$ \\ aUniversity of the Philippines Baguio, Camarines Sur, Bicol, Philippines, mgrace.delavega@gmail.combuniversity of the \\ Philippines Baguio, San del Monte, Bulacan, Philippines, 'University of the Philippines Baguio, Isabela City, Philippines
}

\begin{abstract}
This study looked at the influence of social media usage on the face-to-face family interactions within the home. Its specific purpose was to determine the teenager's perception of the quality of family interactions in relation to the duration and frequency of the teenager's social media usage. An online survey to 100 students was conducted to extract the target population. Ten in-depth interviews were conducted to individuals aged 16 to19 who were identified as heavy users of Facebook and/or Twitter. These 10 students from the University of the Philippines Baguio belong to nuclear families. The qualitative data gathered from the in-depth interviews were analyzed descriptively and interpretively using Time Displacement Theory, Ester Jimenez' Four Dimensions of Family Relationship, and Bandura's concept of Self-Regulation. The presence of four family relationship dimensions, namely, Togetherness, Communication, Discipline, and Nurturance and Affection shaped the students' perceived quality of their family relationships. Findings showed that the media consumption of teenagers is self-regulated so as not to irrationally "displace" the time allotted for highly valued face-to-face family interactions. The researchers determined that time displacement occurred between the teenager's social media usage and academic activities at home but not with the face-to-face interactions with their families.
\end{abstract}

Keywords: Social Media; Family communication; Teenagers; Self-Regulation; Time Displacement

\section{Introduction}

Human communication is inseparable to human existence. One cannot live without conversing and relating to others. It is through communication that individuals learn to actualize themselves and gain understanding of the world. Hence, the absence of communication means the absence of one's self, total isolation, and deprivation of growth and character formation.

Of all the existent communities to which individuals belong, the family serves as the most influential. The family is seen as the primary social group from which individuals first learn to communicate, develop roles, and acquire values. For the most part, they first learn to be a member of the family before being a participant of a larger society. They are regarded as products of everyday face-to-face interactions and meaning-formations at home, a masterpiece molded through times of both nonverbal and verbal exchange of messages.

Amidst the inevitable changes brought by modernization, the family is able to adapt and stand resilient, and thus, keeps on being the "basic institution of society" (Medina 2001, 2). Medina asserted the importance of belonging in a family in one's overall well-being and said that: 
The family is a very close intimate group. The most meaningful relationships are found among family members. The family is the setting of the most intense emotional experiences during the lifetime of the individual-birth, puberty, marriage and death. Thus, the family's influence on personality and character is significant and pervasive. The family affects individual's social values, disposition, and outlook in life. The family is the source of the individual's ideals, aspirations and basic motivations. $(2001,3)$

With the rise of new communication technologies, particularly the Internet and social media, the way individuals and families communicate has changed. It has created a new world in which people may belong to and engage in unexplored endeavors and have their human lives affected in many ways. Among the wonders Internet has brought us is the social media_-web-based services that allow individuals to construct profiles, display user connections, and search and traverse within that list of connections"-which is accessed through the Internet and are considered today as the most prominent 'place' individuals visit. " (Ellison and Boyd 2007, as cited in Davis III et al. n.d., 1) With the advent of such communication technologies, new channels of spending time came along (Davis III et al., 1). Communication and relationships at home are viably affected as the members spend longer time connecting to the social media rather than to the physically present, amply reachable families.

The introduction and spread of social media has built and is building different paths for individuals and their respective families to take. As family members choose to enter the social media world over face-to-face interactions or vice versa, new systemic processes and patterns are emerging within their very home. Thus, changing the cycles and behaviors of the ever dynamic social institution man belongs in. This study aims to determine the influence of social media usage to the quality and quantity of face-to-face family interaction within the home.

Internet has given people access to the larger world of social media. Nevertheless, subscribing to a more technological realm does not always guarantee the betterment of prior interpersonal connections one has. This study grasps and promotes the need to understand the ironic modern reality that individuals, while being connected to the world through social media, have the probability of being disconnected from their very own homes. Thus, this study provokes social awareness on better usage of 'time,' which is upheld as a vital element in communication and relationshipformation within the home, and how social media usage affects face-to-face family communication. Families are not to be studied as groups of interrelated, blood-tied, individuals living together and influencing one another, but groups of interconnected individuals who are now beginning to live in a virtual world (i.e. social media) by means of communication technologies. All these while being physically present at home, thus altering the traditional face-to-face family interactions which served as the foundation of everything the home is and everything the family members are.

Anderson, Afifi, and Guerrero asserted the importance of time in human relationships as it implies the openness and intimacy of people in relationships (2014). A person's importance to one person can be gauged through the amount of time they allot for each other and the amount of time they actually spend together. The level of closeness is reflected by the amount of time people engage in conversations and togetherness. This is why people in romantic relationships strive in making each other feel higher emotional 
closeness through dating, communicating, and exerting time and effort to deepen relationship. Thus, relationships are being invested upon for maintenance and growth.

This study used two theories to construct the framework of analysis: Social Cognitive Theory of Bandura and Time Displacement Theory. Together with these two, Jimenez' indicators of a healthy Filipino family relationship were also applied to determine the quality of relationships the families have.

As part of the socio-psychological tradition, Social Cognitive Theory deals with understanding cognitive and behavioral function of a person. In this theory of Bandura, human behavior is held to be affected by social factors present in his/her environment (Bandura, 1991). Social media has given individuals a new environment—or more likely a virtual societywithin which they can interact. However, Bandura asserts that an individual does not always let the society dictate his/her behaviors, particularly socializing behaviors. Rather, the individual is capable of observing what the society does and uses them as guide, if not the basis, for his/her future actions. Bandura calls this "self-regulation" (Bandura 1991, 248-54).

Time is limited, and humans cannot focus on everything at the same time. According to Nabi and Oliver, Time Displacement Theory asserts the conventional wisdom that says time is a limited resource (2009). Focusing on one thing leads people to attend less or even ignore the others. It assumes that consumption of one media will displace other activities, such as social interaction (Qi et al. 2013). Hence, when people devote their attention on one thing, other things will be given less attention. Nabi and Oliver cited a bunch of researches which remarked how children devoted more time on television viewing than comic reading as compared to the absence of TV before, implying the power of technology to shift users' preferences (2009).
Moreover, this theory assumes that when two activities of the same function or range are present, the one which provides higher satisfaction is chosen and undertaken. Hence, technology was relatively quick to come in the way of print media and other human activities, such as face-to-face interactions.

More so, in order to determine the quality of relationship the family has, Ester Jimenez' concept of four indicators of a healthy family relationship was used (1991). Jimenez conducted a study involving 533 school children to prove the reliability and validity of her Filipino Family Relationship Scale (FFRS) which sought to assess the quality of family relationship (i.e. healthy or unhealthy). She constructed a pictorial scale consisting of 66 pictures in which children were asked to associate their daily family lives. In here study, Jimenez proved the credibility of assessing children's family relationship with these four dimensions: (a) Togetherness, Communication, (c) Nurturance and Affection, and (d) Discipline (1991). In general, these dimensions exemplify that a family that is wellcared and nurtured with affection is composed of family members who do things together, enabling them to communicate with each other, and share each other's thoughts and experiences. Thus, the members would not mind the imposed family rules/system of discipline at home because they believe that it is for order and being fair to everyone (Jimenez 1991).

\section{Method}

For this study, an online survey was conducted among 100 high school and college students to extract the target population of 10 respondents. Then, the researchers set appointments with the final interviewees for data gathering. Respondents were social mediaactive teenagers or heavy users. In-depth 
interviews were conducted to get quantitative and qualitative data which were analyzed and interpreted.

The respondents were University of the Philippines Baguio students from nuclear households in Benguet, Cordillera Administrative Region, Philippines who have their own Internet access at home. Purposive and convenience sampling were used in order to select the necessary unit of respondents who appeared to be adequate representative of the population.

Final respondents were chosen through a set of criteria established by the researchers. The teenager must (a) belong to a nuclear family composed of mother, father, and maximum of four children; (b) be experienced in using communication technologies, specifically the Internet and social media for approximately one year; (c) be active social media users who spend an average of 3 hours every day on Facebook and/or Twitter. Qualified respondents who were in the most convenient proximity to the researchers were chosen, as it helped the researchers to better engage in the study.

\subsection{Data Analysis}

The researchers applied descriptive as well as interpretive analysis to the qualitative and quantitative data collected. Descriptive, as the study provided a vivid, clear, plain visualization of the involved teenagers' family life. Compare and contrast of results from other interviews were made. Interpretive analysis, in addition, served as leeway to a more profound and generative reading of the described phenomena. Influence of time allotted for social media and face-to-face communication was interpreted.

\subsection{Research Instruments}

Online Survey. The researchers utilized Google Docs to create an online survey aimed at determining the population's adherence to the given set of criteria. The survey was conducted among 100 high school and college students in Baguio who are social media users and are currently living with their family whilst studying. Survey respondents whose answers fit the criteria were then pre-interviewed, usually online. Ten of them were selected to be the final interviewees.

Semi-structured Interviews. After obtaining the final set of interviewees through survey and pre-interviews, semi-structured focus interviews were conducted. In conducting personal interviews, the conceptions and experiences of each teenager were articulated and discussed freely, leading the researchers to a concise, profound understanding of how social media usage influences the teenagers' perspectives on family life. This study was set to look at the family realm as penetrated by communication technologies, from the perspective of the ever complicated, technologically-involved teenagers. Individual interviews consumed approximately 1 hour per session. Some respondents needed two to three interview sessions because of their schedule.

Interview Guide. The interview guide was appropriated from Bangsal's study (2014). The researchers created three headings for every set of questions, namely, social media usage, family relationships, and social media usage and face-to-face family interaction. The first heading included questions about the respondents' history of social media use and their insights on such usage. The second heading aimed at delving deeper into the respondents' family life. It included questions about their perceptions on healthy/unhealthy family, family relationships at home, and face-to-face interactions at home. The third and last heading focused on their 
perceived impact of social media usage on faceto-face interactions within the home.

\section{Results and discussion}

For the purpose of this research, the researchers established a set of criteria to evaluate the final interviewees: (a) University of the Philippines Baguio students who are active social media users (i.e. Facebook and/or Twitter), at least one year before the time of the research; (b) a member of a nuclear family; (c) currently living with their families in Baguio and Benguet, Philippines. However, their adherence to the said set of criteria does not mean they are seen as a uniform group of individuals. Respondents were named with letters A to J for their confidentiality.

\subsection{Teenagers' Social Media Usage}

All the respondents are active social media users. Some are equally active in both Facebook and Twitter but most are more active in either of the two. The researchers regarded the respondents as "heavy users" of social media, with reference to the study of Well and Link (2014). According to the study, these "heavy users" spend at least 3 hours on social media every day. Despite their daily schedules in school, all of the respondents manage to visit their accounts at night, when they arrive home. Likewise, the 3-to-5-hour consumption every single day is only an average; their consumption also exceeds to more than 5 hours every day especially on weekends either in a continuous or cumulative basis.

From this study, researchers found out why the respondents engage themselves in social media.

Table 1. Factors Affecting Social Media Usage

\begin{tabular}{lc}
\hline Themes & Frequency of Responses \\
\hline Constant Internet access & 10 \\
Entertainment & 10 \\
Interpersonal utility & 9 \\
Boredom relief & 9 \\
Stress relief & 7 \\
Monitoring of business (e.g. online shop) & 1 \\
For sharing of insights, photos, videos, etc. & 8 \\
\hline
\end{tabular}

Furthermore, respondents' social media activities vary according to the need of the situations they are in. Some became active because they discovered the greater opportunity of connecting with their classmates and friends, checking their friends' online activities, updating oneself on trending topics, and building new relationships. Respondents who use Twitter consider it as a relatively more private domain wherein they can say almost everything they cannot on Facebook, including rants and opinions they do not want their numerous
Facebook friends to read or see. So, it does not matter if these respondents are active users of both or just one, as long as they share a significant insight on social media usage: Facebook and Twitter have served as ways of connecting themselves to a virtual world where they can either vent out or conceal who they are and what they have to say. And yes, they agreed that social media has been an extension of one's self as it has also become a necessity. But no, they said it is not as indispensable in their lives as the air they breathe. 


\subsection{Perceived Openness and Topics Disclosed}

Results show that there exists no single type and culture of family. The respondents of this study manifest that family members have various ways of communicating with one another. Essentially, the respondents' perceived openness and closeness with each of their family members differ. They may feel close to one member but not to the other, depending on the established connection between them.
Findings show that these differences account to the respondents' shared growth and experiences with specific family members. Because families are not comprised of homogenous individuals with homogenous lives, the respondents are seen as communicators whose engagements in diverse series of family interactions lead them to perceive their relationships within the family in a rather disparate fashion. Respondents asserted that as time flies, certain changes in their family lives take place. As members grow older, they may also grow apart, or otherwise.

Table 2. Perceived Openness and Closeness to Parents and Siblings

\begin{tabular}{|c|c|c|c|c|c|c|c|c|c|c|c|}
\hline \multirow{4}{*}{ Respondent } & \multirow{3}{*}{\multicolumn{2}{|c|}{$\begin{array}{l}\text { Perceived } \\
\text { Closeness } \\
\text { to Parents }\end{array}$}} & \multirow{3}{*}{\multicolumn{2}{|c|}{$\begin{array}{l}\text { Perceived } \\
\text { Openness } \\
\text { to Parents }\end{array}$}} & \multirow{3}{*}{\multicolumn{3}{|c|}{$\begin{array}{l}\text { Perceived } \\
\text { Closeness } \\
\text { to Siblings }\end{array}$}} & \multirow{3}{*}{\multicolumn{3}{|c|}{$\begin{array}{l}\text { Perceived } \\
\text { Openness } \\
\text { to Siblings }\end{array}$}} & \multirow{4}{*}{$\begin{array}{l}\text { Do you } \\
\text { perceive your } \\
\text { family is close } \\
\text { as a whole? }\end{array}$} \\
\hline & & & & & & & & & & & \\
\hline & & & & & & & & & & & \\
\hline & Mother & Father & Mother & Father & S1 & S2 & S3 & S1 & $\mathrm{S} 2$ & S3 & \\
\hline A & 7.5 & 7.5 & 7.5 & 5 & 6 & 6 & & 6 & 6 & & YES \\
\hline $\mathrm{B}$ & 11 & 9 & 11 & 11 & 3 & 5 & 13 & 1 & 5 & 13 & $\mathrm{NO}$ \\
\hline $\mathrm{C}$ & 6 & 3 & 6 & 2 & 9 & 6 & 8 & 9 & 7 & 8 & $\mathrm{NO}$ \\
\hline $\mathrm{D}$ & 6 & 7 & 5 & 5 & & & & & & & YES \\
\hline $\mathrm{E}$ & $6-7$ & $5-6$ & $6-7$ & $4-5$ & 9 & 7 & 8 & 7 & 8 & 8 & YES \\
\hline $\mathrm{F}$ & 10 & 8 & 10 & 7 & 7 & & & 7 & & & YES \\
\hline $\mathrm{G}$ & 9 & 6 & 7 & 2 & 7 & 9 & & 7 & 10 & & NEUTRAL \\
\hline $\mathrm{H}$ & 7 & 7 & 10 & 4 & 9 & 9 & & 8 & 9 & & YES \\
\hline I & 9 & 8 & 10 & 10 & 10 & 9 & & 10 & 10 & & YES \\
\hline $\mathrm{J}$ & 8 & 9 & 7 & 10 & 8 & 8 & & 6 & 6 & & YES \\
\hline
\end{tabular}

Respondents weigh intimacy based on decades-long of togetherness, shared experiences, and perceived openness. The researchers noted that the social media usage of the respondents is not an isolated activity to family relationship because it can contribute to the face-to-face interactions at home. Happenings on social media can serve as topics for discussion within the home, especially if it's about a photo or a post about a family relative whom their parents are also interested in.

Most respondents said they are closer and more open to their mothers than their fathers. According to them, their mothers are more interested to their stories and lenient with their mistakes. There are also respondents who said they are closer and more open to their siblings than one or both of their parents. The siblings to whom respondents claimed to be closer and more open are usually older than the respondents, or those whose age is significantly closer to the respondents' age.

\subsection{Social Media Usage and the Filipino Family}

The researchers found that connecting to social media plays a major role in the teenagers' life and in the communication of the family at home. First, social media platforms, specifically Facebook and Twitter, present information and expose issues in the country and the world, enabling the family members to add topics and increase involvement in family discussions within the home. Second, social 
media enables the family members to be updated about activities and events of their relatives and friends despite distance. Third, social media allows the teenagers to communicate through online discussions of topics and concepts. Social media also gives them an extended communication platform with their schoolmates and professors. Fourth, Facebook and Twitter are avenues of the teenagers' feelings and outbursts; sources of information and news in the real world; and systems to build personal and professional connections. Fifth, these social networking sites serve as an "escape" as they venture to the virtual world and create an image of themselves through selecting the information they disclose on the Internet.

With the more accessible Internet subscription today, all respondents have unlimited access to the Internet for social media connection and online interaction. But eight out of the ten respondents said they do not engage in social media during dinner time at home to show respect for their parents and siblings. These eight respondents also said that eating together at dinner is the period wherein family interaction occurs longer. They regard dinner time as a "no gadgets and no Wi-Fi" zone.

Most of the respondents also revealed that they control the information and detail in their posts, since their Facebook friends and Twitter followers include their parents and siblings. Respondents choose to vent out their emotions more in Twitter-a manifestation of a self-regulated social media usage-because some of their family members are not familiar with Twitter yet. The researchers determined that the respondents' family members appointed themselves as "regulators" of the respondents' profiles, so they guard the latter's posts and tweets.

Findings show that most of the respondents have the tendency to work on their academic-related activities while using social media sites at the same time. The respondents said that they try to work on two things simultaneously, but most of the time they fail on accomplishing both—with social media winning their attention. Most interestingly, it was also discovered that respondents do not multi-task face-to-face interactions and social media usage. Only two of them agreed they do. As said in the previous section, respondents see "family time" as something to be valued and unfettered by social media usage. Also, the concentration and attention of the respondents are split between social media and academic-related activities, not necessarily face-to-face communication. Also, respondents noted that the worst case that can happen to them is the diversion of their whole time for academic requirements to Facebook and Twitter usage.

Results show that social media has a relatively feeble influence on the respondents' face-to-face family interactions. Most of the respondents said that the quality of their communication with parents and siblings are still the same. Among the most notable insights gathered is that the influence of social media on face-to-face interactions primarily depends on the kind of family with whom a teenager lives. Likewise, the perceived quality of family relationships established prior to the advent of social media plays a crucial role on how respondents gauge the influence of their heavy social media usage on their family communication.

It was expected that as the respondents connect to Facebook and Twitter, they are disconnected from their family. It was presumed that the time for face-to-face interaction is replaced and lessened as the respondents engage in social media on an average of 3 to 5 hours every day. Yet, the researchers determined otherwise. The respondents then asserted that the impact largely 
depends on how the heavy-user member of social media uses social media, either as virtual escape from the home or a mere diversion of attention from the stress of academics and other areas of life.

Despite the respondents' heavy social media usage, majority of them claimed that social media "reinforced" face-to-face interactions at home and "strengthened" family relationships. Findings show that change in the attitudes and behaviours of a teenager is influenced by various factors, and social media plays a relatively minor role. Two respondents revealed that social media provided topics for discussion, such as current events and trending topics, as they read it on their Facebook newsfeed and as what their family read in the newspapers and watches in television. It was found that there was no change in the respondents' attitude toward their interaction with their family.

Results also show that in the presence of social media, the four dimensions that make up a healthy family need to be strengthened. The kind of family relationships established before the respondents became heavy users of social media serves as the fundamental foundation of how they perceive the quality of family interaction. Basically, the respondents who view their family relationships as healthy and close as a whole have the tendency to regard social media usage as a mere addition to their everyday activities, not a substitute to the still treasured face-to-face interactions.

Despite the overwhelming urge for social media usage, heavy users do not right away displace their activity to another; it is subject to regulation. Respondents consume social media (i.e. Facebook and/or Twitter) with the knowledge of limited time, leading them to regulate usage in order to maintain other activities they interminably value-face-to-face family communication. Therefore, the researchers found that time allotted for social media usage does not take away the time for face-to-face interaction. Instead, it takes away from the time allotted for other non-media related activities such as academic matters and interests. As this happens, the perceived quality of face-to-face communication within the home remains dependent on the teenagers' regard for their family, not necessarily on their individual social media usage at home. Teenagers claimed that social media can help deepen and strengthen the bond of the family, as it opens up a new world where the family can discuss more topics and extend the concept of home. Amidst all this, when teenagers lose the connection to social media, they still have the chance to connect to their homes, to their families.

Finally, respondents asserted that family is the basic unit of the society wherein an individual is taught to love, care, and support other family members. They agreed that family is the foundation of interpersonal relationships. The development of attitudes and behaviours of family members is manifested in the home first. And with the advent of social media, the family is now faced with the challenge of establishing or maintaining a close family relationship and an open line of family communication. This is a phenomenon present in the respondents' homes and of which they are fully aware. However, respondents agreed that their definitions of a healthy family are not drastically changed by the introduction of social media to the Filipino homes. Social media makes the family more vulnerable to fragmentation, but the respondents argued that as family members treasure and protect what they have, good family relationships will prevail.

\section{Conclusion}

The purpose of this study is to define the influence of the respondents' social media usage on their face-to-face family interactions at 
home. Its aim was to: explore the duration and frequency of social media usage and the factors influencing it; and explore the face-to-face interaction habits of the respondents and the factors influencing it. The framework includes Time Displacement Theory which proposes the inability of human beings to simultaneously attend to different activities. Findings show that such idea is true to the respondents. The respondents have an ample amount of time to spend on various activities they find worth engaging in; activities like, Facebook and/or Twitter usage, family bonding, attending to academic matters (e.g. studying, writing academic papers), and pursuing interests and hobbies.

The researchers found that duration and frequency of social media usage is a cutback to the time allotted for academic matters, and interests and hobbies, but not to the time spent on face-to-face interactions within the home. Albert Bandura says in his Theory of SelfRegulation that one chooses to engage in activities not by mere impulse but by forethought (1991). In this study, it was noted that respondents do not use social media without regard to its consequences. Selfregulation is evident in the respondents' apparent discontinuation of social media usage when they deem certain situations as opportunities for face-to-face family communication. Likewise, respondents regulate the content of their social media accounts for they are aware of their parents' and siblings' virtual presence hence they re-think before they click the "post" and "tweet" buttons.

As expected, face-to-face family interaction was regarded as the most essential element that sets the edifice of a family. After years of using social media, it has also served as a valued part of their everyday lives. Thus, the researchers considered the significance of exploring the respondents' perception of their family interaction in relation to their social media usage. Consistent with the Four Dimensions of Family Relationship: (a) togetherness, (b) communication, (c) discipline, and (d) nurturance and affection, findings show that the four dimensions are not perceived as isolated elements of family relationship (Jimenez, 1991). An isolated view of the said dimensions creates an incomplete concept of a healthy family. For instance, family togetherness in itself does not make a healthy family when devoid of open communication.

The researchers conclude that the social media engagement of a teenager who belongs to a nuclear family does not automatically change his or her prior relationships with family members - a stark contrast to the expected results that social media usage lessens the time teenagers spend on face-to-face family interactions within the home. So, the researchers recommend that as early as possible, parents must create a good and established relationship with their young children. Examples are, based on the respondents' experiences, eating meals together at least once a day - good for catchingup; spending time together on weekends; watching movies together; celebrating holidays and special occasions together; initiating deep conversations; helping each other out - with chores, assignments, problems with friends in school; or, simply sharing about how everybody's day went. Researchers observed that the respondents started living their own lives during or after their high school education. And during college, there is not enough time for their family to bond together like they used to. However, most respondents still see the importance of family time, thus they long for it. On the other hand, some respondents are only starting to form a good-quality family relationship in their college days now, because of, according to them, maturity. Therefore, the researchers suggest that parents must grab every opportunity to bond with their child as early as possible, so that even though social media or the 
Internet becomes more powerful in the future, the good, if not intimate, family relationship will be maintained.

The researchers suggest future researchers to expand the range and number of target population in order to collect more responses from a variety of teenagers coming from other locations. Since this study was limited to teenagers belonging to nuclear families, future research can target teenagers who belong to a different kind of family structure such as an extended family or a singleparent family. Lastly, aside from conducting an in-depth interview and qualitative data-gathering technique, a quantitative research can possibly help future researchers. A quantitative approach in determining the exact amount of time teenagers spend using social media and amount of time spent for face-to-face interactions a day can further strengthen the analysis of the former's effects on the latter.

\section{Reference}

Andersen, P., Afifi, W., \& Guerrero, L. (2014). Close Encounters: Communication in Relationships. Thousand Oaks, California, 4th Edtion. Retrieved from SAGE.

Bandura, A. (1991). Social Cognitive Theory of Self-Regulation. Organizational Behavior and Human Decision Processes,(50), 248-287. Retrieved from http://www.uky.edu/ eushe2/Bandur a/Bandura1991OBHDP.pdf.

Bangsal, M. C. V. (2014). The Filipino Family 2.0: A Comparative Study on the Actual and Virtual Manifestations of the Filipino Value Close Family Ties. . Retrieved from http://iskwiki.upd.edu.ph/flipbook/vie wer/?fb=2010-32671-The-Fili\#page-1

Davis, C. F., III, Deail-Amen, R., Rios-Aguilar, C., \& Canche, M. (n.d.). Social Media in Higher Education: A Literature Review and Research Directions. Retrieved March 4, 2015, from https://www.academia.edu/1220569/S ocial Media in Higher Education A Literature Review and $\mathrm{R}$ esearch Directions.

Jimenez, E. (1991). Development and Validation of a Filipino Family Relationship Scale. Ph.D Thesis: University of the Philippines Diliman.

Medina, B. (2001). The Filipino Family (2nd ed.). Diliman, Quezon City: University of the Philippines Press.
Nabi, R.L., \& Oliver, M.B. (2009). Displacement Effects. The SAGE Handbook of Media Processes and Effects, edited by Jennings Bryant and Wes Fondren, 505--15. California: SAGE Publications, Inc. Retrieved from https://books.google.com.ph/books?id $=$ scvuAwAAQBAJ\&pg = PT522\&lpg $=$ PT522\&dq $=\mathrm{McCombs}+\mathrm{ti}$ me + displacement + theory\&source $=$ bl $\&$ ots $=\operatorname{lgBxNiAv\& sig}=$ NHvoeq 3 YgdJzz3 ZpxNPH3wa571w\&hl=en\&sa $=$ X\&ei $=$ XN4rVbCHGuHJmAWwkoHwDg\&ve $\mathrm{d}=0$ CEYQ6AEwB.

Qi, E., Shen J., \& Dou R., eds. (2013). The 19th International Conference on Industrial Engineering and Engineering Management. Springer Science \& Business Media. Retrieved April 9, 2015 from https://books.google.com.ph /books?id=7fNHAAAAQBAJ\&pg=PA $741 \& \operatorname{lpg}=\mathrm{PA} 741 \& \mathrm{dq}=\mathrm{Nie}+$ and + displa cement + theory\&source $=$ bl\&ots $=$ fdINi $\mathrm{X} 850 \mathrm{~K} \&$ sig $=\mathrm{BUpchYzeFkWH7xHjPT}$ $8 \mathrm{Av} 4 \mathrm{q} 6 \mathrm{Mgs} \& \mathrm{hl}=$ en\&sa $=\mathrm{X} \& \mathrm{ei}=7 \mathrm{x} 0 \mathrm{sVd}$ qPFc_hoASQp4G4DA\&ved=0CFEQ6 $A E w C Q \#_{v}=$ onepage\&q $=N i e \% 20$ and $\% 20$ displacement $\% 20$ theory\& $\mathrm{f}=$ false.

Well, T., \& Link, M. (2014). "Facebook User Research Using a Probability-Based Sample and Behavioral Data." Journal of Computer-Mediated Communication 19, no. 4: 1042--52. doi:10.1111/jcc4.12058. 